\title{
Ulcerative colitis accompanied by aseptic abscesses syndrome and small-vessel vasculitis
}

\author{
Bartłomiej Wawrzycki', Grażyna Chodorowska', Aldona Pietrzak', Andrzej Prystupa², Witold \\ Krupski $^{3}$, Maria Majdan ${ }^{4}$, Jerzy Mosiewicz² ${ }^{2}$ Dorota Krasowska' \\ ${ }^{1}$ Chair and Department of Dermatology, Venerology and Paediatric Dermatology, Medical University of Lublin, Poland \\ ${ }^{2}$ Chair and Department of Internal Diseases, Medical University of Lublin, Lublin, Poland \\ ${ }^{3}$ II Department of Radiology, Medical University of Lublin, Poland \\ ${ }^{4}$ Department of Rheumatology and Connective Tissue Diseases, Medical University of Lublin, Poland
}

Wawrzycki B, Chodorowska G, Pietrzak A, Prystupa A, Krupski W, Majdan M, Mosiewicz J, Krasowska D. Ulcerative colitis accompanied by aseptic abscesses syndrome and small-vessel vasculitis. J Pre-Clin Clin Res. 2016; 10(2): 140-143. doi: 10.5604/18982395.1227574

\section{Abstract}

Introduction. Cutaneous small-vessel vasculitis and aseptic abscesses syndrome are among the rarest extraintestinal manifestations of bowel inflammatory diseases.

Materials and methods. The study describes the case of a 19-year-old female admitted to the Department of Dermatology due to cutaneous small-vessel vasculitis. In order to reach the final diagnosis, a wide spectrum of laboratory and diagnostic tests were performed. Three subsequent abdominal CT scans confirmed the presence of hypodense foci, initially in the spleen, and subsequently in the liver. The aseptic abscesses syndrome was diagnosed based on the radiological picture and the exclusion of infectious causes of the above-described foci.

Objective. Presentation of a case of concomitance of cutaneous small vessel vasculitis and septic absecess, accompanied by inflammatory bowel disease.

Results. During the hospitalisation, the patient developed symptoms of paralytic ileus. The results of colonoscopy and biopsy of intestinal mucous membrane were typical of ulcerative colitis.

Conclusions. To the best of the authors' knowledge, this is the first presentation of ulcerative colitis accompanied by aseptic abscesses syndrome concomitant with cutaneous small vessel vasculitis.

\section{Key words}

leukocytoclastic vasculitis, aseptic absecesses, inflammatory bowel disease

\section{INTRODUCTION}

Vasculitis forms a heterogeneous group of diseases characterised by primary involvement of vascular structures by an inflammatory process causing damage to vascular walls, and in the case of disrupted blood supply to body organs - to their dysfunction $[1,2,3,4]$.

Leucocytoclastic or hyperergic vasculitis $(\mathrm{LcV})$ is the most common form of cutaneous small-vessel vasculitis $[5,6,7]$. In $45-55 \%$ of cases the cause of the vasculitis remains unknown, in $15-20 \%$ of patients it is preceded by an (bacterial, fungal or viral) infection, in $15-20 \%$ connective tissue disorders or inflammatory bowel diseases (IBD) are the causative factor, $10-15 \%$ is triggered by drugs, while neoplasms are responsible for approximately $5 \%$ of cases $[8,9,10]$.

The aseptic abscesses syndrome (AA) belongs to a group of autoinflammatory diseases. It is characterised by the presence of deep abscesses, which are the consequence of accumulation of neutrophils, detected on radiological tests, negative results of blood and abscess aspirate cultures, and no response to antimicrobial agents and rapid post-glucocorticosteroid (GCS) improvement $[11,12,13,14]$.

In the majority of described cases, aseptic abscesses occur in the spleen (70\%), lymph nodes of the abdominal cavity (53\%), liver (40\%), lungs (17\%), pancreas (10\%), brain (10\%),

Address for correspondence: Bartłomiej Wawrzycki, Chair and Department of Dermatology, Venerology and Paediatric Dermatology, Medical University of Lublin, Radziwiłłowska 13, 20-080, Lublin, Poland

E-mail: bartekwawrzycki@o2.pl

Received: 27 February 2016; accepted: 28 September 2016 and sometimes also in the soft tissues. A relationship between the AA syndrome and the inflammatory bowel diseases, and neutrophilic dermatoses has been described [11, 12].

\section{OBJECTIVE}

The aim of this study is to present the case of concomitance of cutaneous small-vessel vasculitis and aseptic abscesses syndrome, accompanied by inflammatory bowel disease.

\section{CASE STUDY}

A 19-year-old female patient was admitted to the Department of Dermatology because of pleomorphic skin eruption consisting of indurative erythema, blisters, tumours and ulcerating tumours located on the lower legs, accompanied by joint contractures and oedema (Fig.1a-d).

Since 2008, the patient has been hospitalised several times, diagnosed with pseudomembranous enterocolitis (2008), erythema nodosum (2009), and Weber-Christian disease (2010). During each hospitalization, laboratory tests showed: leucocytosis - $15.8 \mathrm{~K} / \mu \mathrm{l}$, anaemia $(\mathrm{Hgb})-9.3 \mathrm{~g} / \mathrm{dl}$, RBC $3.86 \mathrm{M} / \mu \mathrm{l}$, thrombocythaemia (PLT) $-678 \mathrm{~K} / \mu \mathrm{l}$, neutrophilia (Neu) $-8.06 \mathrm{~K} / \mu \mathrm{l}$, (Neu) $-76.8 \%$, increased CRP $-81.8 \mathrm{mg} / \mathrm{l}$, and ESR - 58/h.

A histopatological examination of the lesional skin biopsy revealed a picture indicative of leucocytoclastic vasculitis, which was further confirmed by direct imunnofluorescence 


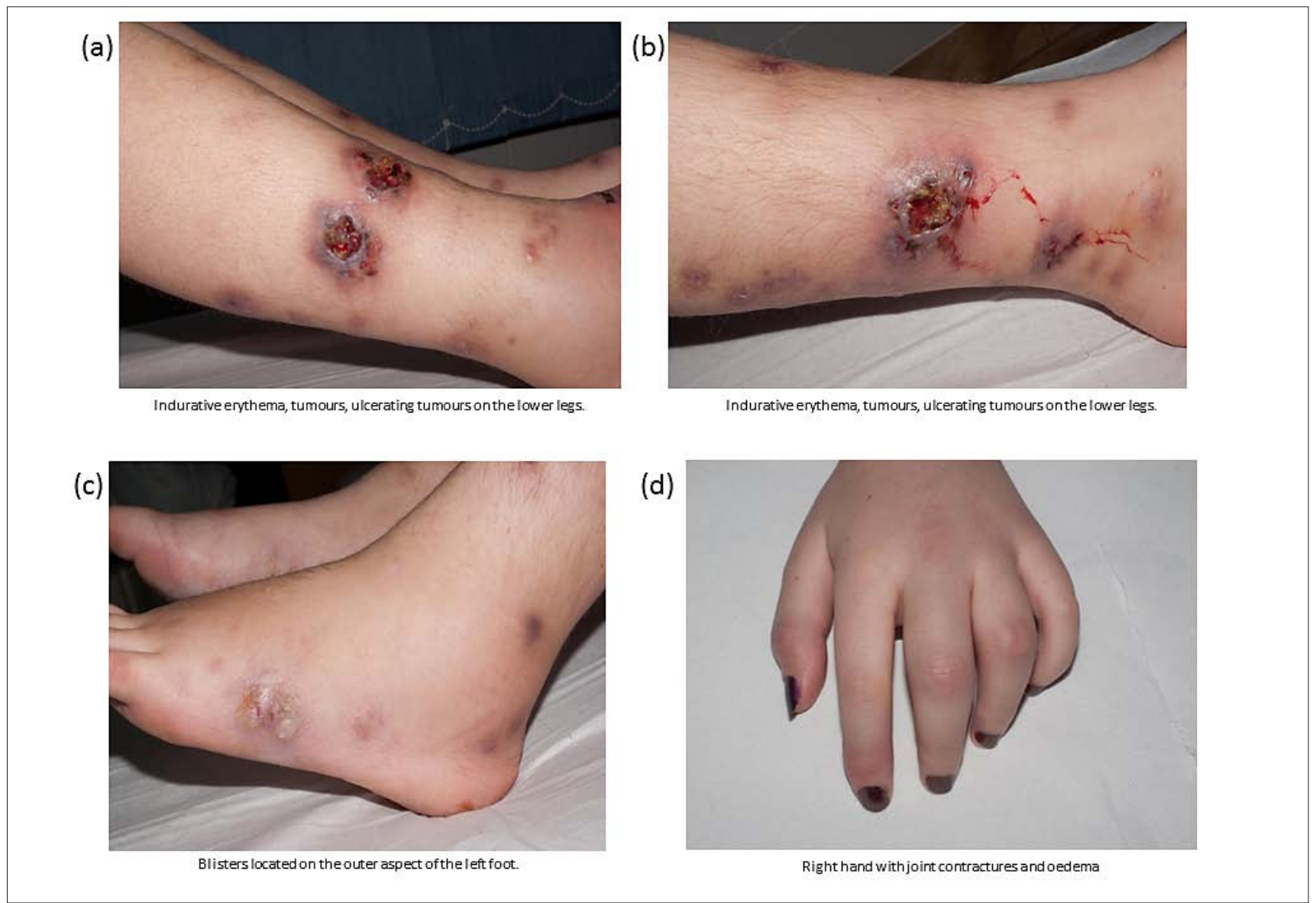

Figure 1.

of the collected sample showing IgM immunoglobulin and C3 deposits in the vessel walls.

The patient underwent a number of diagnostic tests which excluded connective tissue diseases, infections and neoplasms. No infectious agents were identified either by mycological and bacterial cultures, nor by the Grocott and Ziehl-Neelsen staining of the biopsied lesions. Additionally, no infections were identified either in pantomographic rtg and throat cultures. A series of blood culture tests showed no bacterial growth; serological test results did not confirm an infection caused by Borrelia burgdorferi, Chlamydia trachomatis, Treponema pallidium or Mycoplasma.

To establish a differential diagnosis of bowel inflammatory lesions, tests for antibodies to Yersinia enterocolica, Yersinia pseudotuberculosis and Quantiferon tests were carried out. No parasites or Clostridium difficile toxins A and B were identified in a stool sample. Viral test results (antibodies to HIV, EBV, HCV, RNA-HCV, anti-HBs) were negative.

In order to exclude systemic connective tissue diseases and systemic vasculitis, the levels of anti-nuclear antibodies (ANA, ds-DNA, ASMA, LKM, pANCA, cANCA), anticardiolipin antibodies, cryoglobulins, antibodies to $\beta 2$ glycoprotein and C3, C4 complement components were determined. All the test results were within normal reference limits. The levels of Ca125, AFP, CEA tumour markers were also within normal limits.

In order to differentiate focal lesions in the liver, a blood serum test for tapeworm (Western-Blot) (E. granulosus, E. multilocularis), aspergillosis and systemic candidiasis (ELISA) were carried out with negative results.
Doppler ultrasound of lower-limb vessels showed no vascular pathologies or thrombosis.

Three months prior to the current hospitalization, the patient underwent an abdominal CT scan which showed the presence of hypodense lesions with a diameter of $15 \mathrm{~mm}$, localised in the spleen (3 lesions) and the liver (2 lesions in segments 6 and 8) (Fig. 2a) which suggested metastatic lesions.

However, during the current period of hospitalisation, 2 abdominal CT scans were carried out with negative results for focal lesions in the spleen (Fig. 2b).

A hypodense focus in segment 5 of the liver was identified on the first CT scan (Fig. 2c). The next scan performed 7 days later, showed the same lesion, and additionally a lesion in segment 7 (Fig. 2d).

In the meantime, the patient experienced a sudden increase in body temperature - up to $39^{\circ} \mathrm{C}$, symptoms of abdominal tympany, and bright red blood in per rectum examination. An abdominal X-ray was therefore carried out which showed symptoms of paralytic ileus (megacolon toxicum) - widening of and high fluid levels in the bowels. Abdominal ultrasound results showed fluid in the Morison's pouch. After the symptoms of paralytic ileus subsided, the patient underwent a colonoscopy. The colonoscopy results showed multiple ulcerations in the large intestine, with easy bleeding, covered with fibrin and mucosal oedema in the intestine. The lesions observed in the colonoscopy were classified in accordance with the Mayo Endoscopic Scoring of Ulcerative Colitis scale as Stage 3 lesions. The clinical presentation, endoscopic and histopathological test results 
(a)

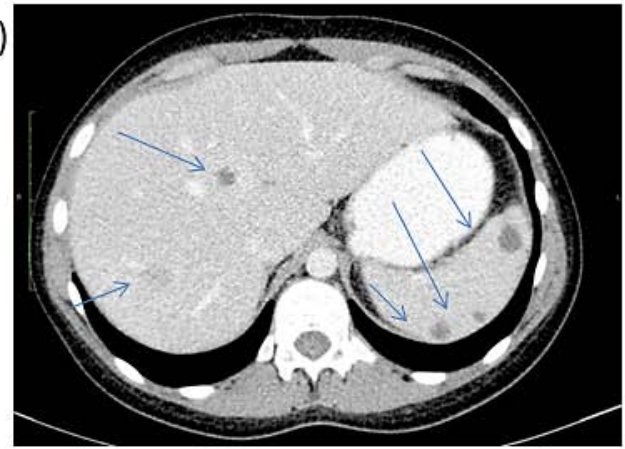

Abdominal CT performed in April 2010. Round hypodensic areas in the 6th and 8 th segment of liver.

(c)

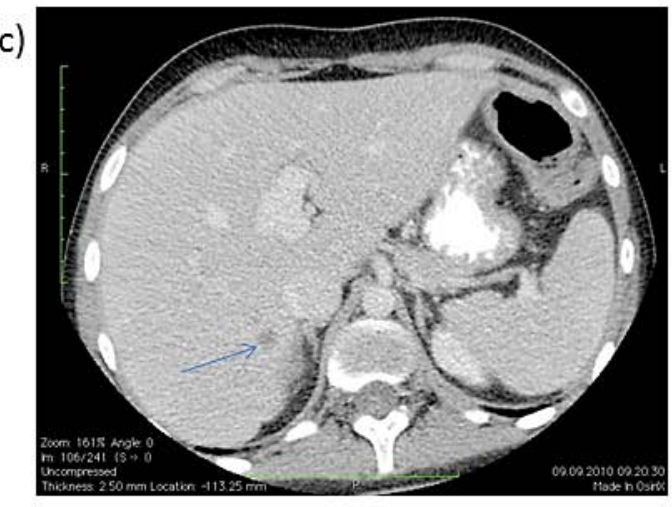

First abdominal CT performed in September 2010. Round hypodensic area in the 5th segment of liver. (b)

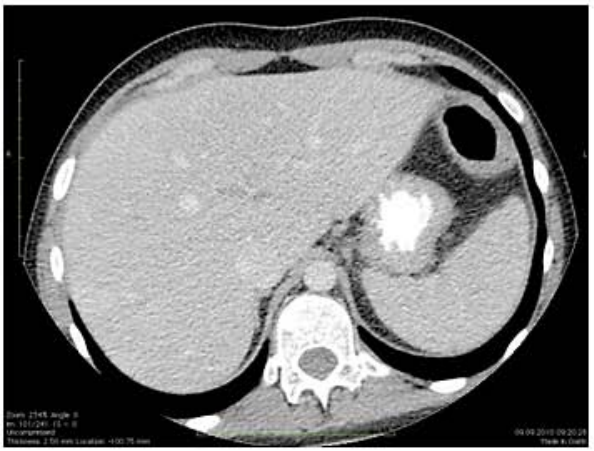

Abdominal CT performed inSeptember 2010. On the same level like in Fig.2A there areno hypodensic lesions.

(d)

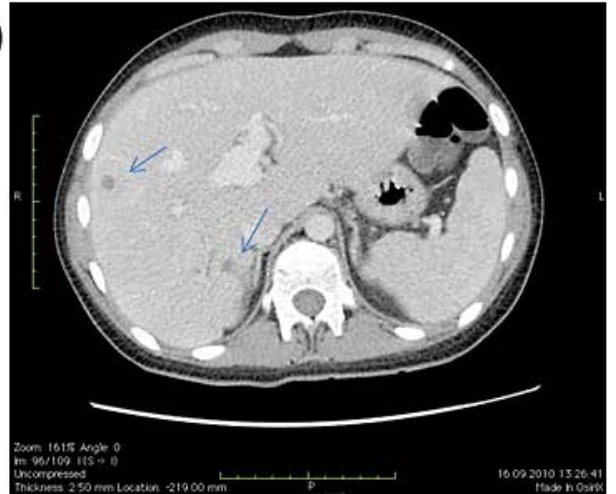

Second a bdominal CT performed inSeptember 2010. On the same level like in Fig.2C there are two hypodensic lesions in the 5 th and 7 th segment of liver.

Figure 2.

were indicative of ulcerative colitis. The treatment included GCS, azathioprine and mesalazine, which resulted not only in resolution of intestinal symptoms, but also in near complete clearing of skin lesions.

\section{DISCUSSION}

To the best of the authors' knowledge, this is the first presentation of ulcerative colitis accompanied by aseptic abscesses syndrome, concomitant with cutaneous smallvessel vasculitis.

Chronicity and recurrence of skin eruptions in association with persistent anaemia, thrombocythaemia, elevated levels of inflammatory response markers suggested secondary nature of cutaneous lesions.

In the presented case, the diagnosis of cutaneous smallvessel vasculitis was confirmed by the results of histopathology and direct immunofluorescence (DIF) examinations $[15,16$, $17,18]$.

The diagnosis of ulcerative colitis was established based on the histopathological picture of the intestinal biopsy in connection with the typical course of the disease complicated by paralytic ileus.

The aseptic abscesses syndrome was diagnosed based on the overall clinical presentation, abdominal CT scans which showed significant dynamics of lesions according to imaging test results, concomitance of ulcerative colitis, laboratory test results - exclusion of infectious background (blood culture test, serological tests for Yersinia enterocolica, Quantiferon), leucocytosis and elevated ESR.

The aseptic abscesses syndrome as described by Andre et al. $[11,12]$ is a group of clinical and pathological symptoms which include: young age, fever, abdominal pain, leucocytosis, elevated ESR. The imaging test results reveal hypodensic, abscesses-like usually of multi-focal distribution, localised mostly in the spleen, liver, abdominal lymph nodes and sometimes outside the abdominal cavity, e.g. in the lungs, pancreas and brain $[11,12]$.

In $7 \%$ of cases lesions can be localised more superficially in the form of skin abscesses, sometimes with the involvement of superficial lymph nodes, muscles, pharynx or testicles. A proportion of affected patients will have also some articular complaints, such as arthritis and arthralgia. These symptoms do not respond to antimicrobial therapy, while regressing rapidly after GCS therapy or biologic agents $[12$, 19, 20].

The AA syndrome is accompanied by IBD in $66 \%$ of cases and by neutrophilic dermatoses in $20 \%$ of cases (e.g. Sweet's syndrome and pyoderma gangrenosum). There are also reports about concomitance of AA with rheumatoid arthritis or Weber-Christian disease [12, 18, 19, 20, 21]. The syndrome does not seem to be invariably accompanied by the conditions referred to above. Cases have been described in which the aseptic abscesses syndrome preceded or occurred subsequent to the above-listed disorders.

Andre et al. [12] suggested a number of diagnostic criteria for the aseptic abscesses syndrome (Tab. 1). The patient's 
condition in the presented case complied with all these criteria.

The proper diagnosis of all the lesions was confirmed by the effective treatment of both bowel lesions and secondary skin lesions after administration of GCS and immunosuppressants.

\section{CONCLUSIONS}

Ulcerative colitis can be accompanied by aseptic abscesses syndrome and cutaneous small-vessel vasculitis; however, both the diagnosis and efficient treatment are difficult. It is therefore necessary to ensure the good collaboration of a number of specialists, as well as carryng out a wide spectrum of laboratory and imaging tests.

\section{REFERENCES}

1. Stone JH. The classification and epidemiology of systemic vasculitis In: Firestein GS, Budd RC, Harris ED, McInnes IB Jr, Shaun R, Sergent JS (ed) Kelley's Textbook of Rheumatology, 8th edn. Saunders, Philadelphia; 2009: pp 1401-1408.

2.Stone JH. Immune Complex-Mediated Small Vessel Vasculitis. In: Firestein GS, Budd RC, Harris ED, McInnes IB Jr, Shaun R, Sergent JS (ed) Kelley's Textbook of Rheumatology, 8th edn. Saunders, Philadelphia; 2009: pp 1465-1473.

3. Jennette JC, Falk RJ, Bacon PA, Basu N, Cid MC, Ferrario F, et al. Revised International Chapel Hill Consensus Conference Nomenclature of Vasculitides. Arthritis Rheum. 2013; 65(1): 1-11.

4. Sunderkötter C, Sindrilaru A. Clinical classification of vasculitis. Eur J Dermatol. 2006; 16 2): 114-24.

5. Fiorentini DF. Cutaneous vasculitis. Jam Acad Dermatol. 2003; 48: 311-40.

6.Xu LY, Esparza EM, MD, Anadkat MJ, Crone KG, Brasington RD. Cutaneous manifestations of vasculitis. Semin Arthritis Rheum. 2009; 38: $348-360$
7.Iglesias-Gamarra A, Restrepo JF. Small-vessel vasculitis. Current Rheumatol Rep. 2007; 9: 304-311.

8. Gonzalez-Hay MA, Garcia-Porrua C, Pujol RM. Clinical approach to cutaneous vasculitis. Curr Op In Rheumatology. 2005; 17: 56-61.

9. Ekenstam Eaf, Callen JP. Cutaneous leukocytoclastic vasculitis. Clinical and laboratory features of 82 patients seen in private practice. Arch Dermatol. 1984; 120(4): 484-9.

10. Stone JH, Nousari HC. "Essential" cutaneous vasculitis: what every rheumatologist should know abort vasculitis of the skin. Curr Opinion in Rheumatology. 2001; 13: 23-34.

11. André MF, Piette JC, Kémény JL, Ninet J, Jego P, Delèvaux I, Wechsler B, Weiller PJ, Francès C, Blétry O, Wismans PJ, Rousset H, Colombel JF, Aumaître O. Aseptic abscesses: a study of 30 patients with or without inflammatory bowel disease and review of the literature. Medicine (Baltimore). 2007; 86(3): 145-61.

12. André M, Aumaître O. Aseptic abscesses syndrome. Rev Med Interne. 2011; 32(11): 678-88.

13. Andre MF, Aumaitre O, Grateau G, Chamaillard M, CostedoatChalumeau N, Cardoso MC, et al. Longest form of CCTG microsatellite repeat in the promoter of the CD2BP1/PSTPIP1 gene is associated with aseptic abscesses and with Crohn disease in French patients Digestive Diseases \& Sciences. 2010; 55(6): 1681-8.

14. Andre MF, Aumaitre O, Piette JC, Grateau G, Cardoso MC, Ouchchane $\mathrm{L}$, et al. Analysis of the NOD2/CARD15 gene in patients affected with the aseptic abscesses syndrome with or without inflammatory bowel disease Digestive Diseases \& Sciences. 2008; 53(2): 490-9.

15. Carlson JA. The histological assessment of cutaneous vasculitis. Histopathology. 2010; 56: 3-12.

16. Kawakami T. New algorithm (KAWAKAMI algorithm) to diagnose primary cutaneous vasculitis. J Dermatol. 2010; 37: 113-124.

17. Carlson JA, Cavaliere LF, Grant-Kels JM. Cutaneous vasculitis: diagnosis and management. Clin Dermatol. 2006; 24: 414-429.

18. Chen K-R, Carlson JA. Clinical approach to cutaneous vasculitis. Am J Clin Dermatol. 2008; 9(2): 71-92.

19. Ito T, Sato N, Yamazaki H, Koine T, Emura I, Saeki T. A case of aseptic abscesses syndrome treated with corticosteroids and TNF-alpha blockade. Mod Rheumatol. 2013; 23: 195-199.

20. Bardy A, Guettrot-Imbert G, Aumaitre O, AndreMF. Efficacy of IL-1B blockade of refractory aseptic absecesses syndrome. Mod Rheumatol. 2013; DOI10.1007/s10165-012-0826-3.

21. Fukuda S, Nanki T, Morio T, Hasegawa H, Koike R, Miyasaka N. Recurrent mitral valve regurgitation with neutrophil infiltration in a patient with multiple aseptic abscesses. Mod Rheumatol. 2012. DOI10.1007/s10165-012-0793-8 